\title{
Is the Isolated-Tip Needle-Knife Precut as Effective as Conventional Precut Fistulotomy in Difficult Biliary Cannulation?
}

\author{
Tae Hoon Lee ${ }^{1}$, Sang-Heum Park ${ }^{1}$, Jae Kook Yang ${ }^{1}$, Su Jung Han ${ }^{1}$, Suyeon Park ${ }^{2}$, Hyun Jong Choi ${ }^{3}$, Yun Nah Lee ${ }^{3}$, \\ Sang-Woo $\mathrm{Cha}^{4}$, Jong Ho Moon ${ }^{3}$, and Young Deok $\mathrm{Cho}^{4}$ \\ ${ }^{1}$ Department of Internal Medicine, Soonchunhyang University School of Medicine, Cheonan, ${ }^{2}$ Department of Biostatistics, Soonchunhyang \\ University School of Medicine, Seoul, ${ }^{3}$ Department of Internal Medicine, Soonchunhyang University School of Medicine, Bucheon, and \\ ${ }^{4}$ Department of Internal Medicine, Soonchunhyang University School of Medicine, Seoul, Korea
}

Background/Aims: Needle-knife precut fistulotomy (NK-F) is a well-known freehand technique for difficult biliary cannulation (DBC). Another approach involves the use of Iso-Tome ${ }^{\circledR}$, a modified precutting device with an insulated needle tip to prevent direct thermal injury. This comparative study aimed to evaluate the efficacy of the Iso-Tome ${ }^{\circledR}$ precut (IT-P) compared to that of NK-F for DBC. Methods: Patients with a naïve papilla who underwent early IT-P or NK-F for DBC were enrolled. DBC was defined as failure to achieve selective biliary access by wire-guided cannulation despite 5 minutes of attempted cannulation, $\geq 5$ papillary contacts, or a hooknose-shaped papilla. The primary endpoint was the primary technical success rate, which was based on a noninferiority model. Results: A total of 239 DBC cases were enrolled. The primary technical success rates were $74.7 \%$ (89/119) in the IT-P group and 91.6\% (110/120) in the NK-F group (lower limit of $90 \%$ confidence interval, -0.23 ; $p=0.927$ for a noninferiority margin of $10 \%$ ). The total technical success rates were $87.4 \%$ and $95.0 \%$, respectively $(p=0.038)$. The mean precutting times for successful biliary access were 11.2 minutes for IT-P and 7.3 minutes for NK-F $(p<0.01)$. The procedure-related adverse event rates were $9.2 \%$ for IT-P and $5.8 \%$ for NK-F ( $p=0.318$ ). The rates of post-endoscopic retrograde cholangiopancreatography pancreatitis were $4.2 \%$ and $2.5 \%$, respectively ( $p=0.499$ ). Conclusions: IT-P failed to exhibit noninferiority compared with NK-F regarding the primary technical success rate of DBC, but there was no difference in the frequency of adverse events. (Gut Liver 2018;12:597605)

Key Words: Cannulation; Biliary; Precut; Iso-Tome; Needleknife

\section{INTRODUCTION}

Despite the various endoscopic techniques available to facilitate selective biliary access, selective biliary cannulation may be incomplete in up to $18 \%$ of patients, although this falls to $\leq 5 \%$ in experienced hands. ${ }^{1,2}$ Therefore, various endoscopic techniques, such as guidewire-assisted cannulation, double guidewire-induced cannulation, precut papillotomy, or transpancreatic sphincterotomy with or without placement of a pancreatic stent, have been used to improve cannulation success rates. ${ }^{3-9}$ Among them, precut sphincterotomy as a rescue method was first introduced by Siegel in $1980 .^{8}$

Initial reports warned of the risk of complications such as post-endoscopic retrograde cholangiopancreatography (ERCP) pancreatitis, and recommended that precut sphincterotomy should be performed only by experienced endoscopists. However, the prolonged procedure time for cannulation, the excessive manipulation causing ampullary edema and injury, and repeated unintentional pancreatic duct (PD) cannulation before the trial of the precut itself have been shown to be independently associated with increased risks of post-ERCP pancreatitis (PEP)., ${ }^{3,10-12}$ Meta-analyses of precut sphincterotomy and conventional cannulation attempts in patients with difficult biliary cannulation (DBC) stated that the rate of PEP was lower with the precut technique, while those of successful biliary cannulation and complications did not differ. ${ }^{4}$ Currently, precut fistulotomy using needle-knife (NK) is the preferred technique in DBC by an experienced endoscopist.

Especially regarding precut fistulotomy, it may not contact the main PD directly, and does not significantly increase the severity of pancreatitis. Early institution of precut in DBC can improve the successful cannulation rate without increasing the

Correspondence to: Sang-Heum Park

Department of Internal Medicine, Soonchunhyang University School of Medicine, 31 Suncheonhyang 6-gil, Dongnam-gu, Cheonan 31151, Korea

Tel: +82-41-570-3662, Fax: +82-41-574-5762, E-mail: pparksh@schmc.ac.kr

Received on December 21, 2017. Revised on February 1, 2018. Accepted on February 19, 2018. Published online June 22, 2018

pISSN 1976-2283 eISSN 2005-1212 https://doi.org/10.5009/gnl17572

@ This is an Open Access article distributed under the terms of the Creative Commons Attribution Non-Commercial License (http://creativecommons.org/licenses/by-nc/4.0) which permits unrestricted non-commercial use, distribution, and reproduction in any medium, provided the original work is properly cited. 
frequency of complications, such as PEP. Indeed, one recent report showed that NK-precut fistulotomy (NK-F) might also be feasible and safe as an initial procedure for biliary access in patients with choledocholithiasis who are at high risk of PEP. ${ }^{13}$

Another precut tool, the NK papillotome, Iso-Tome ${ }^{\circledR}$ (MTW Endoskopie, Wesel, Germany), has an isolated, semi-ovalshaped tip to reduce direct electric or thermal damage caused by the tip of the incising needle. ${ }^{14}$ This modification might facilitate its use and reduce direct thermal and electrical injury, as well as direct mechanical trauma to the PD by controlling the depth of needle penetration during incision.

Our group previously reported the technical feasibility of Iso-Tome ${ }^{\circledR}$ precut (IT-P) in failed primary biliary cannulation, but the technical feasibility of a single-armed approach or retrospective results from a single user have been described. ${ }^{14-16}$ Therefore, this prospective comparative study evaluated the technical feasibility and procedure-related adverse event rates of IT-P compared with traditional precut fistulotomy using a conventional NK regarding DBC.

\section{MATERIALS AND METHODS}

\section{Study design and main outcomes}

This study was performed as a single-center, prospective, randomized, noninferiority trial. The primary endpoint was the primary technical success rate of IT-P and NK-F for selective biliary access regarding the DBC; that is, an initial wire-guided cannulation time $\geq 5$ minutes, $\geq 5$ papillary contacts, or a hooknose-shaped papilla. The secondary endpoints were procedurerelated adverse events and overall procedure outcomes. Randomization was performed by assigning patients according to a computer-generated random number list with a 1:1 allocation, using a random block size of four, by a contributing statistical physician. When the patients meet the DBC criteria, open the random number list by assisting nurse and randomized IT-P or NK-F group. We obtained informed consent prior to ERCP from all patients. This study was performed following confirmation of Institutional Review Board approval. The protocol has been registered in the Clinical Trial Registration database (http://www. cris.nih.go.kr/KCT0001960), and followed the Consolidated Standards of Reporting Trials (CONSORT) guidelines.

\section{Patients}

Patients with a naïve papilla who needed therapeutic ERCP were enrolled in a tertiary referral center between November 2015 and December 2016. Therapeutic ERCP was defined by abdominal ultrasonography, computed tomography, or magnetic resonance imaging (or magnetic resonance cholangiopancreatography) with or without endoscopic ultrasonography (EUS). Patients initially planned to undergo diagnostic ERCP were not enrolled in this study. The inclusion criteria were as follows: (1) failed conventional biliary cannulation according to the DBC criteria (see definition); (2) no serious or uncontrolled medical illness; and (3) provision of informed consent. Exclusion criteria included patient age $<18$ years, uncorrectable coagulopathy, history of allergy to radiocontrast agents, inaccessible papilla, surgically altered anatomy, and refusal to participate in the study. Patients with $\geq 3$ unintentional PD cannulations were also not included according to the inclusion criteria and suggested procedure algorithm (Fig. 1).

\section{Endoscopic techniques}

All patients underwent ERCP (TJF-240 or 260V; Olympus Optical Co., Ltd., Tokyo, Japan) in the left lateral decubitus or prone position after endoscopic sedation. Patients were sedated using a balanced propofol sedation: initial intravenous administration of midazolam $(0.05 \mathrm{mg} / \mathrm{kg}$ body weight; $1 \mathrm{mg}$ if age $\geq 70$ years or American Society of Anesthesiologists (ASA) class III-IV) and fentanyl (12.5 to $50 \mu \mathrm{g})$, followed by repeated doses of 10 to $20 \mathrm{mg}$ of propofol with maintenance of sedation with repeated doses of 10 to $20 \mathrm{mg}$ of propofol to achieve a moderate level of sedation, or midazolam and fentanyl-based sedation at identical doses. Prophylactic antibiotics or analgesics were permitted. A nonsteroidal anti-inflammatory drug suppository for the prevention of PEP was not used in this study because it is not available in domestic. Carbon dioxide insufflation was employed during the endoscopic procedures. The VIO 300D electrosurgical generator (Erbe, Tübingen, Germany) was used for electrocurrent (cutting mode: ENDOCUT, effect 2 or 3, cut duration 2, and interval 3).

Initially, all selective cannulation of the common bile duct

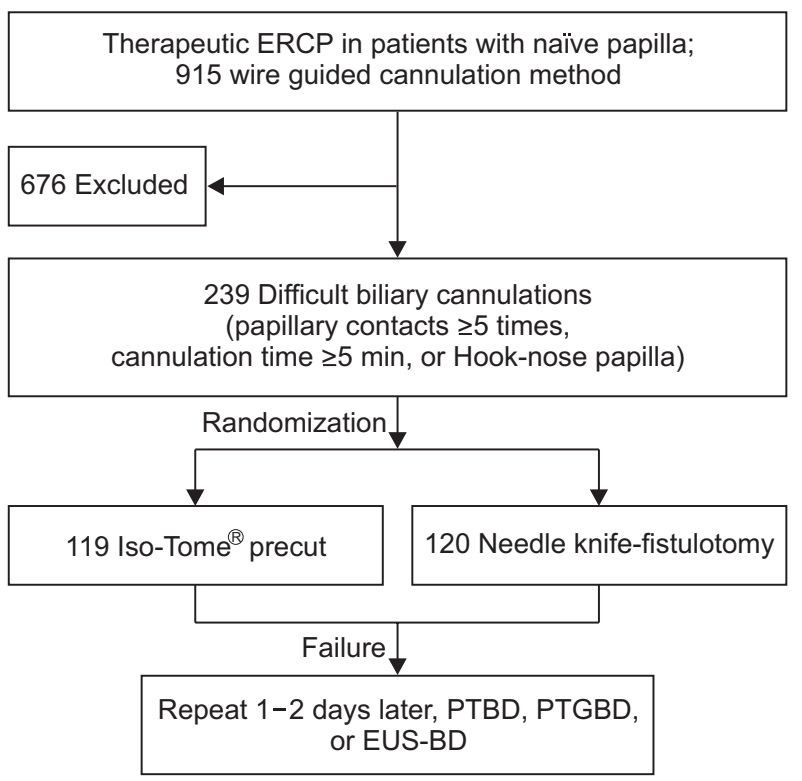

Fig. 1. Flow diagram of the study.

ERCP, endoscopic retrograde cholangiopancreatography; PTBD, percutaneous transhepatic biliary drainage; PTGBD, percutaneous transhepatic gallbladder drainage; EUS-BD, endoscopic ultrasound-guided biliary drainage. 
(CBD) was attempted using a standard wire-assisted biliary cannulation technique. A hydrophilic-tipped Hydra Jagwire (Boston Scientific, Natick, MA, USA) or Tracer Metro (Cook Medical, Winston-Salem, NC, USA), 0.035 inches in a diameter, was preloaded into a pull-type papillotome (flow cut, Olympus Optical; DASH ${ }^{\circledast}$ sphincterotome, Cook Medical). The papillotome was oriented from the 11 o'clock to the 12 o'clock position on the major papilla and bowed to align correctly with the axis of the bile duct. Following minimal insertion of the pull-type papillotome into the major papilla, the guidewire was carefully advanced through the CBD under fluoroscopic guidance until it was observed to enter the bile duct. If the PD was entered, the guidewire was simply withdrawn and redirection toward the CBD was attempted.

\section{1) Iso-Tome ${ }^{\circledR}$ precut}

The insulated tip of the Iso-Tome ${ }^{\circledR}$ was placed in the orifice of the ampulla of Vater (AV), and tension was applied to the cephalad rim when selective access to the CBD failed according to the DBC criteria. During application of electrocurrent, the Iso-Tome ${ }^{\circledR}$ was intentionally pulled further toward the papillary roof at the 11 to 12 o'clock position to avoid direct contact with the orifice of the main PD. Stepwise precutting was repeated until pinkish bile duct mucosa was clearly identified. Then, selective biliary cannulation was attempted using a guidewire technique (Fig. 2). After selective biliary cannulation was suc-
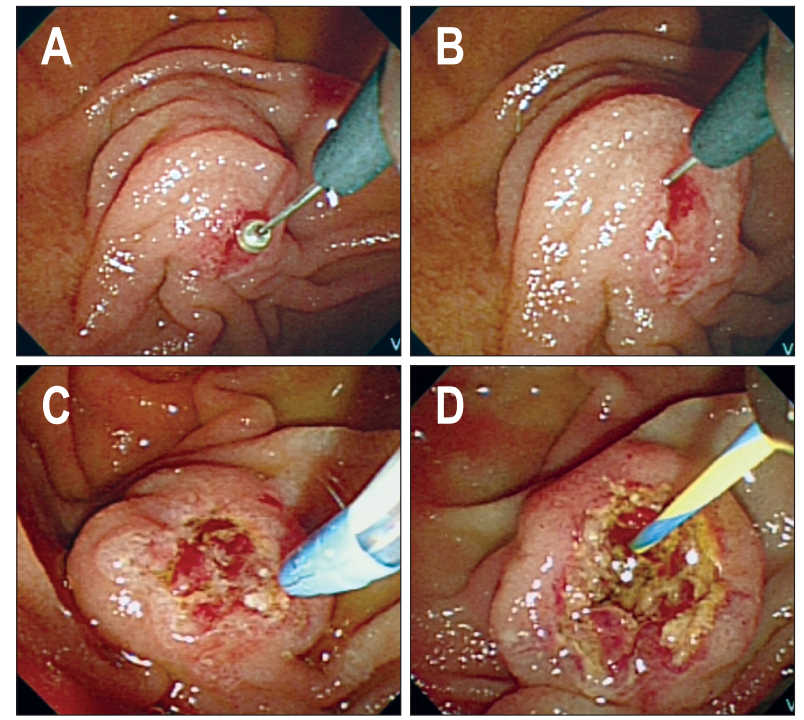

Fig. 2. Endoscopic Iso-Tome ${ }^{\circledR}$ precut technique. (A) Duodenoscopy showed a prominent ampulla of Vater (AV) with erythema due to primary cannulation failure. The Iso-Tome ${ }^{\circledR}$ was introduced at the orifice to perform the precut. (B) The isolated tip of the Iso-Tome ${ }^{\circledR}$ was placed at the orifice of the AV, and then precutting was performed with slight upward tension in the 11 to 12 o'clock direction. (C) Following successful precut, the intrapapillary mucosa was noted, and conventional guidewire cannulation was attempted. (D) Successful wire-guided bile duct cannulation using a papillotome was achieved. cessfully achieved, an extended endoscopic sphincterotomy was performed using a standard pull-type papillotome, NK (extended endoscopic sphincterotomy, extended EST) or endoscopic transpapillary pneumatic balloon dilation (EPBD), according to the therapeutic purpose. ${ }^{14-16}$

\section{2) Needle-knife precut fistulotomy}

An NK-F (Microtome; Boston Scientific) was also performed as an early rescue technique when selective access to the CBD failed according to the DBC criteria. Fistulotomy was initiated over the maximal bulging portion of the $\mathrm{AV}$ and then extended upwards or downwards little by little. However, the incision stopped short of the papillary orifice or papillary roof to prevent duodenal perforation (Fig. 3). After the incision into the intraduodenal segment of the CBD, when bile trickled out from the incision site, the bile duct was negotiated using a guidewirepreloaded NK. An additional extended EST by NK or EPBD was also performed according to the therapeutic purpose. ${ }^{17}$

In this study, PD stent placement to enhance primary biliary access or routine prophylactic placement to prevent PEP was not planned. However, in cases of difficult precutting with unintentional PD cannulation ( $\leq 2$ times) during selective biliary cannulation, a PD stent was placed during the endoscopic procedure. A PD stent was also considered in cases of a difficult precut, based on the decision of the endoscopists. A 5 F, singlepigtail pancreatic stent (Cook Medical) was used in these cases.

When selective biliary cannulation failed in both IT-P and NK-P, we attempted the second trial using the same method
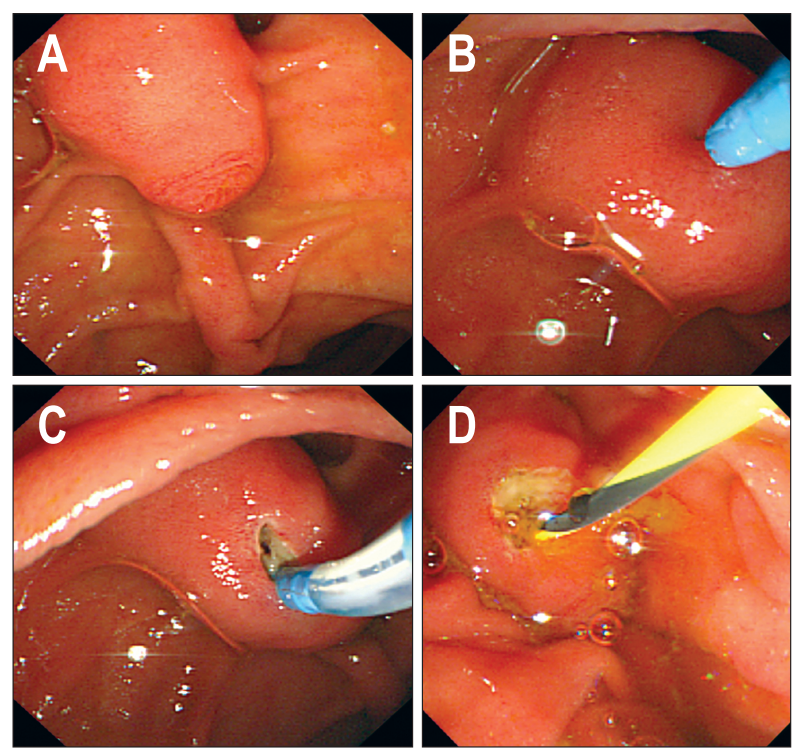

Fig. 3. Endoscopic conventional needle-knife (NK)-fistulotomy technique. (A) Duodenoscopy showed a bulging ampulla of Vater (AV). (B) NK incision started at the maximal bulging point of the papillary roof of the AV. (C) Following small incremental incisions in the papillary roof, guidewire insertion was attempted using NK. (D) Successful bile duct cannulation was achieved. 
1 or 2 days later. If urgent drainage was needed in cases with sepsis, subsequent percutaneous transhepatic biliary drainage (PTBD), percutaneous transhepatic gallbladder drainage (PTGBD), or EUS-guided biliary drainage was scheduled on the same day. All endoscopic procedures were performed by two experienced endoscopists with at least 10 and 5 years of experience using the Iso-Tome ${ }^{\circledR}$, and more than 13 and 8 years of experience with NK-precut. Trainees were not involved in this study.

\section{Definitions}

The DBC criteria were defined based on the previous studies $;^{3,10,11,18}$ failure to achieve selective biliary access by wireguided cannulation despite 5 minutes of attempted cannulation after duodenal intubation (cannulation time $\geq 5$ minutes), five or more papillary contacts, or a hook-nose-shaped papilla. Meaningful papillary contact was defined as sustained contact of the guidewire-preloaded papillotome with the AV for at least 3 to 5 seconds of manipulation..$^{10,11,19,20}$ As a difficult criteria, the configuration of a hook-nose-shaped papilla was included based on previous reports (Fig. 4). ${ }^{10,11}$ Conventional access with a wire-assisted papillotome may be difficult in hook-nose type papilla because the AV orifice is located at the far distal lower side much like the nostrils of a hooknose. In cases with three, or more than three unintentional PD cannulations, an NK precut from the orifice of the AV was performed following placement of a prophylactic PD stent according to the algorithm. Patients with PD stent-assisted selective biliary access were not included in this study according to the protocol (Fig. 1).

Primary technical success was defined as an intended initial technical success by IT-P or NK-P. Total technical success included primary and secondary technical success. Secondary technical success was defined as a retrial using the same method 1 or 2 days later when primary selective biliary cannulation failed in either IT-P or NK-P. Endoscopic therapeutic success is any type of procedure outcomes such as insertion of biliary stent or removal of stones after selective biliary access. Cannulation time was calculated as the time elapsed between duodenal intubation and initiation of precut. The precut time was the interval between initiation of precut and either successful biliary cannulation or termination of the procedure on the video monitoring system. Total procedure time was from initiation of precut to completion of endoscopic procedures. Post-ERCP adverse events including pancreatitis were classified according to consensus guidelines. ${ }^{21}$

\section{Statistical analysis}

The primary outcome analysis was a noninferiority comparison of IT-P and NK-F regarding primary technical success rates on an intention-to-treat principle. From our two reported pooled analysis studies of NK-F, we assumed that the primary technical success rate for NK-F was 93.7\%. ${ }^{10,11}$ We set a margin of noninferiority for a technical success rate of 10\% (this noninferiority margin of 10\% would be clinically relevant) according to the results of a pooled analysis and after discussion with the contributing physician. Calculation of the sample size was based on a margin of noninferiority for a technical success rate of 0.1 . To achieve a statistical power of $80 \%$ with the assumption of a type I error rate of 5\%, a total of 222 patients (111 per group) was calculated. Assuming a 5\% drop-out rate, we calculated a final sample size of 234 patients (117 per group). Sample size and power were calculated using the PASS version 12 software (NCSS, Kaysville, UT, USA). The noninferiority hypothesis for the primary outcome was assessed using the Z-test with the lower limit of a 90\% confidence interval (CI) in the technical success rate and margin of noninferiority. The $90 \%$ CI of this difference was reported because one-sided 5\% significance was used for the sample size calculation. In our study, a two-sided $90 \% \mathrm{CI}$, which corresponds to a one-sided significance level of 0.05 , was used for the primary outcome. ${ }^{22}$ The characteristics of the study groups were compared using a t-test or MannWhitney test for continuous variables and chi-squared or Fisher exact test for categorical variables. A probability level of $\mathrm{p}<0.05$ was considered to indicate statistical significance. All analyses were performed using STATA version 13.1 (Stata Corp., College Station, TX, USA).
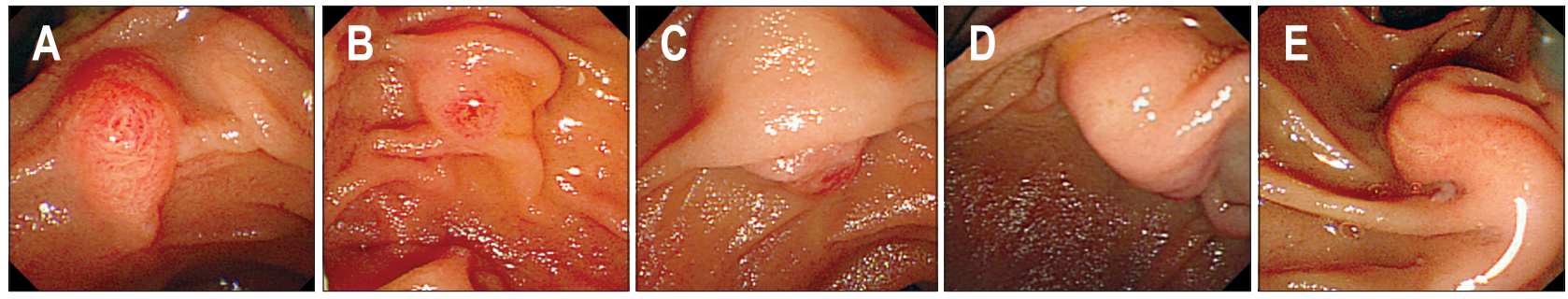

Fig. 4. Various ampulla of Vater (AV) configurations. (A) Non-prominent type: a small papilla without marked oral protrusion of the papillary roof. (B) Prominent type: more prominent elevation of the papillary roof. (C) Bulging type: marked swelling from the bulge in the papillary roof to the oral ridge of the duodenal wall. (D) Hook-nose type: a huge bulging type with an invisible AV orifice due to a hook-nose-shaped protrusion. (E) Distorted type: AV of unusual shape and distorted position due to tumor invasion or compression. 


\section{RESULTS}

\section{Analyses of baseline characteristics}

A total of 915 patients underwent therapeutic ERCP during the study period. Among them, 676 patients were excluded for the following reasons: successful selective biliary cannulation $(n=597)$, uncontrolled coagulopathy $(n=3)$, surgically altered anatomy $(n=5)$, duodenal obstruction $(n=5)$, and patients who underwent precut following placement of a PD stent due to more than three unintentional PD cannulation $(n=66)$. Finally, a total of 239 primary cannulation failure patients with a naïve papilla (119 IT-P and 120 NK-P) were enrolled and randomized according to strict DBC criteria (Fig. 1). Baseline characteristics did not differ between the two groups. The indications for ERCP did not differ between the two groups. The most common indication for ERCP was choledocholithiasis $(62.2 \%$ in the IT-P group vs $62.5 \%$ in the NK-F group). The configuration of the $\mathrm{AV}$ also did not differ between the two groups. Non-prominent, prominent, and bulging-type AVs were the most common types in both groups. A hook-nose-shape was evident in 22 patients (18.5\%) in the IT-P group, and 17 patients (14.2\%) in the NK-P group (Table 1).

\section{Primary outcome analysis}

The primary technical success rates for selective biliary cannulation were $74.7 \%(89 / 119)$ in the IT-P group and $91.6 \%$ $(110 / 120)$ in the NK-F group (lower limit of 90\% CI, $-23 \%$; $\mathrm{p}=0.927$, for a noninferiority margin of $10 \%$ ). The difference was not significant, and the $90 \% \mathrm{CI}$ was below the noninferiority margin. The total technical success rates, including secondary success, were 87.4\% (104/119) and 95.0\% (114/120), respectively $(\mathrm{p}=0.038)$. The total technical success rate in the IT-P group was also lower than the NK-F group (Table 2). The cannulation time before initiation of precut did not differ between the two groups. The mean precut times from initiation of precut to successful biliary access were 11.26 minutes in the IT-P group and 7.31 minutes in the NK-F group, respectively $(\mathrm{p}<0.01)$ (Table 3).

\section{The reasons for precut, primary cannulation failure, and management}

The most common cause of precut was $\geq 5$ papillary contacts in both groups (61.3\% and 63.3\%). The primary causes of selective biliary cannulation failure were a non-prominent AV, improper targeting, distortion or bulging of AV due to tumor invasion, an overhanging circular mucosal fold, and paradoxical reaction in the IT-P group. In the NK-PF group, a nonprominent AV, improper targeting, and distortion or bulging of the AV due to tumor invasion were the principal causes. Cases of secondary cannulation failure in the IT-P group underwent PTBD with maintenance of external drainage $(n=1)$, PTBD with the rendezvous method $(n=7)$, PTGBD $(n=2)$, and surgery $(n=2)$. The remaining three patients were managed conservatively due to their refusal to undergo second endoscopic or interventional procedures. The patients who underwent PTGBD received in-

Table 1. Baseline Characteristics

\begin{tabular}{lcc}
\hline \multicolumn{1}{c}{ Characteristic } & TT-P $(\mathrm{n}=119)$ & NK-F $(\mathrm{n}=120)$ \\
\hline Age, yr & $62.93 \pm 16.16$ & $66.03 \pm 14.68$ \\
Sex, M/F & $58 / 61$ & $53 / 67$ \\
Diagnosis & & \\
Choledocholithiasis & $74(62.2)$ & $75(62.5)$ \\
Gallbladder stone/cholecystitis & $4(3.4)$ & $7(5.8)$ \\
Malignant biliary obstruction & $23(19.3)$ & $25(20.8)$ \\
Gallstone pancreatitis & $14(11.8)$ & $10(8.3)$ \\
Biliary stricture & $1(0.8)$ & 0 \\
Bile leak & 0 & $2(1.7)$ \\
Choledochocele & $1(0.8)$ & $1(0.8)$ \\
Suspected SOD & $2(1.7)$ & 0 \\
Use of anticoagulation or antiplatelet drugs & $18(15.1)$ & $14(11.7)$ \\
Papilla configuration & & \\
Non-prominent & $30(25.2)$ & $34(28.3)$ \\
Prominent & $30(25.2)$ & $30(25.0)$ \\
Bulging & $32(26.9)$ & $30(25.0)$ \\
Distorted & $5(4.2)$ & $9(7.5)$ \\
Hook-nose shape & $22(18.5)$ & $17(14.2)$ \\
\hline
\end{tabular}

Data are presented as mean \pm SD or number $(\%)$.

IT-P, Iso-Tome ${ }^{\circledR}$ precut; NK-F, needle-knife precut fistulotomy; M, male; F, female; SOD, sphincter of Oddi dysfunction. 
terval cholecystectomy. Patients in the NK-F group underwent PTBD with maintenance of external drainage $(n=1)$, PTBD with the rendezvous technique $(n=2)$, EUS-guided biliary drainage $(n=2)$, and surgery $(n=1)$ (Table 4).

\section{Therapeutic procedure outcomes and adverse events}

Regarding therapeutic procedure outcomes, the final endoscopic therapeutic success rates (including the endoscopic success after radiologic interventions such as PTBD or PTGBD) were 93.3\% in the IT-P group and 98.3\% in the NK-F group, respectively $(\mathrm{p}=0.059)$. The total procedure times were 31.20 and 23.74 minutes, respectively $(\mathrm{p}<0.01)$. The prevalence rates of extended EST or EPBD were similar in the two groups. Fifteen patients $(12.6 \%)$ in the IT-P group and 24 patients $(20.0 \%)$ in the NK-F group underwent PD stent placement $(\mathrm{p}=0.122)$. Among them, 13 patients (10.9\%) in the IT-P group and 23 patients (19.2\%) in the NK-F group experienced at least one unintentional pancreatic guidewire cannulation (Table 3).

Regarding procedure-related adverse events, PEP developed in five patients (three mild and two moderate) in the IT-P group and three patients (all mild) in the NK-F group ( $\mathrm{p}=0.499)$. No severe PEP developed in either group. One case of periampullary microperforation was detected in the IT-P group and was managed conservatively without additional serious complications. No other serious complications or mortality occurred (Table 3).

\section{DISCUSSION}

Previously, the most popular techniques for precut sphincterotomy were cutting upward from the papilla orifice or downward toward the orifice. Incising above the papilla, on its roof, without touching the orifice was not commonly performed. However, NK-F is now considered the preferred free-hand technique for selective biliary access in DBC to improve successful cannulation rates without increasing the frequency of complications, such as pancreatitis. ${ }^{4,8-11,23-30}$

Besides the well-known NK, the Iso-Tome ${ }^{\circledR}$ was developed to decrease the frequency of PEP and enhance selective biliary

Table 2. Technical Success Rates of Selective Biliary Cannulation Using IT-P and NK-F

\begin{tabular}{|c|c|c|c|c|}
\hline No. $(\%)$ & IT-P & NK-F & $\begin{array}{c}\text { Difference between IT-P and } \\
\text { NK-F }(90 \% \mathrm{CI})\end{array}$ & $\mathrm{p}$-value \\
\hline Primary technical success & $89 / 119$ (74.7) & $110 / 120$ (91.6) & $-0.17(-0.23$ to -0.11$)$ & $0.927^{*}$ \\
\hline Total technical success & $104 / 119(87.4)$ & $114 / 120$ (95.0) & & $0.038^{\dagger}$ \\
\hline
\end{tabular}

IT-P, Iso-Tome ${ }^{\circledR}$ precut; NK-F, needle-knife precut fistulotomy; CI, confidence interval.

${ }^{*}$ Noninferiority was defined as a lower limit of $90 \% \mathrm{CI}$ greater than $-10{ }^{\dagger}{ }^{\dagger}$ Pearson chi-square test.

Table 3. Overall Procedure Outcomes and Adverse Events

\begin{tabular}{|c|c|c|c|}
\hline & IT-P (n=119) & NK-F $(n=120)$ & p-value \\
\hline Cannulation time till precut, min & $4.63 \pm 1.96$ & $4.88 \pm 2.28$ & 0.369 \\
\hline Precut time, min & $11.26 \pm 8.11$ & $7.31 \pm 6.88$ & $<0.01$ \\
\hline Procedure time, min & $31.20 \pm 15.29$ & $23.74 \pm 11.62$ & $<0.01$ \\
\hline Overall endoscopic therapeutic success* & $111(93.3)$ & $118(98.3)$ & 0.059 \\
\hline \multicolumn{4}{|l|}{ Therapeutic procedures } \\
\hline Extended EST & $30(25.2)$ & $27(22.5)$ & 0.623 \\
\hline EPBD & $64(53.8)$ & 59 (49.2) & 0.475 \\
\hline Biliary stent & $24(20.2)$ & 35 (29.2) & 0.196 \\
\hline Metal/plastic & $4(3.4) / 20(16.8)$ & $9(7.5) / 26(21.7)$ & - \\
\hline Pancreatic stent placement & $15(12.6)$ & $24(20.0)$ & 0.122 \\
\hline Unintentional PD cannulation $\leq 2$ times & $13(10.9)$ & $23(19.2)$ & 0.075 \\
\hline Adverse events & $11(9.2)$ & $7(5.8)$ & 0.318 \\
\hline Pancreatitis & $5(4.2)$ & $3(2.5)^{\dagger}$ & 0.499 \\
\hline Bleeding & $3(2.5)$ & $5(4.2)^{\dagger}$ & 0.722 \\
\hline Cholangitis & $2(1.7)$ & $1(0.8)$ & 0.622 \\
\hline Perforation & $1(0.8)$ & 0 & 0.498 \\
\hline
\end{tabular}

Data are presented as mean \pm SD or number $(\%)$.

IT-P, Iso-Tome ${ }^{\circledR}$ precut; NK-F, needle-knife precut fistulotomy; EST, endoscopic sphincterotomy; EPBD, endoscopic transpapillary balloon dilation; PD, pancreatic duct.

*Included primary and secondary endoscopic procedures; ${ }^{\dagger}$ In the NK-F group, two cases of pancreatitis with bleeding occurred. 
access. Theoretically, IT-P is available as a primary classical precut method from the orifice of AV in an upward direction, but without direct PD injury by an insulated needle tip. Although the clinical outcomes and technique of IT-P were reported, these studies were conducted as a retrospective single-arm. ${ }^{14-16}$ In the first comparative study of the insulated tip papillotome and classic precut sphincterotomy, the technical success and complication rates were similar. ${ }^{31}$ However, technically the initial cannulation method was not standardized. A pull-type sphincterotome with or without guidewire assistance was used. Also, there was no consideration of unintentional PD cannulation. Moreover, precut fistulotomy is preferred over the classic precut sphincterotomy.

In presented noninferiority trial, we used wire-assisted cannulation only as an initial cannulation method. We also applied strict biliary cannulation criteria and difficult AV configuration as a definition of DBC to compare the efficacy of IT-P and NK-F. Frequent unintentional PD cannulation ( $\geq 3$ times) was excluded from this comparison because prophylactic PD stentassisted precut or cannulation was effective and safe regarding reducing the severity of PEP. The results showed that the primary technical success rate of IT-P was not comparable to that of traditional NK-F. Also, precut time till successful biliary access or termination, and total procedure time were greater in the IT-P group than in the NK-F group. In patients who underwent IT-P, following successful incision, an additional conventional sphincterotome or papillotome was required for selective biliary access or extension of the incision site for subsequent procedures. Because the IT-P does not have a working channel for a guidewire, and repeated step-wise IT-P and use of a sphincterotome or papillotome are required for successful biliary access. This might result in prolonged precut and procedure times with IT-P. However, there was no difference in the frequency of procedure-related adverse events. IT-P in cases of DBC was also safe and not associated with a higher complication rate even though the incision started from the orifice of the AV.

Compared with three previous single-armed studies of precut using Iso-Tome ${ }^{\circledR},{ }^{14-16}$ the total technical success rate was similar (87.4\% in the present study vs $86.4 \%$ to $94.3 \%$ in the previous studies). However, the primary technical success rate in this study was considerably lower (74.7\%). Regarding the complication rate, in the first pilot study of Iso-Tome ${ }^{\circledR}$, the complication rate was 28\%. ${ }^{14}$ However, two subsequent studies reported complication rates of $2.9 \%$ to $6.8 \%,{ }^{15,16}$ possibly due to the timing of precut after the failure of conventional cannulation. Early precut than delayed rescue use might reduce the rate of adverse events. The overall complication rate in the present study was 9.2\%. Regarding NK-F, the technical success and complication rates were comparable to those reported previously., ${ }^{4,11}$

Regarding the causes of technical failure of IT-P, a non-prominent $\mathrm{AV}$ was the most common cause of primary cannulation failure. IT-P requires hooking onto the orifice of the AV and

Table 4. Causes of Precut and Precut Failure as Well as Management

\begin{tabular}{lll}
\multicolumn{1}{c}{ No. $(\%)$} & IT-P $(\mathrm{n}=119)$ & NK-F $(\mathrm{n}=120)$ \\
\hline Indication of precut & & $76(63.3)$ \\
Papillary contacts $\geq 5$ times & $73(61.3)$ & $27(22.5)$ \\
Cannulation time $\geq 5$ min & $24(20.2)$ & $17(14.2)$ \\
Hook-nose shape & $22(18.5)$ & $10(8.3)$ \\
Primary causes of precut failure & $30(25.2)$ & 3 \\
Non-prominent ampulla of Vater & 9 & 3 \\
Improper targeting* & 7 & 4 \\
Distortion or bulging d/t tumor invasion & 7 & 0 \\
Overhanging circular mucosal fold & 5 & 0 \\
Paradoxical reaction ${ }^{\dagger}$ & 2 & $6(5.0)$ \\
Management of secondary failure & $15(12.6)$ & 1 \\
PTBD with keeping drainage catheter & 1 & 2 \\
PTBD with rendezvous & 7 & 0 \\
PTGBD & 2 & 2 \\
EUS-guided biliary drainage & 0 & 1 \\
Surgical intervention & 2 & 0 \\
Conservative treatment & 3 & 0.138 \\
\hline
\end{tabular}

Data are presented as number (\%).

IT-P, Iso-Tome ${ }^{\circledR}$ precut; NK-F, needle-knife precut fistulotomy; PTBD, percutaneous transhepatic biliary drainage; PTGBD, percutaneous transhepatic gallbladder drainage; EUS, endoscopic ultrasonography.

*Due to rapid bowel movement, rapid breathing, or anatomical variation during precut; ${ }^{\dagger}$ Unexpected endoscopic sedation (midazolam)-related adverse event. 
upward incisional traction. Therefore, a non-prominent or flat papilla with a narrow roof or overhanging circular mucosal fold can complicate the creation of an adequate but safe incision. In addition, improper targeting can make it difficult to place/hook the IT-P onto the orifice of the AV. Nevertheless, although this technique was performed by endoscopists experienced with IsoTome $^{\circledR}$, the overall failure rate was too high. Stricter indication criteria and training with this device may be warranted. However, the frequency of adverse events did not differ between the two groups. The PEP rate and severity of pancreatitis were also not different between the groups. Despite the high technical failure rate of IT-P, the PEP frequency did not increase, perhaps due to the insulated tip, which did not directly contact the PD.

To perform a successful precut, besides adequate equipment, adequate time for the precut and sufficient experience are required. First, the adequate timing of precut may be related to the DBC criteria. A delayed or rescue trial may increase the rate of adverse events. So, based on previous results, we used the following strict DBC criteria: cannulation time $\geq 5$ minutes, $\geq 5$ papillary contacts, or a hook-nose-shaped papilla. ${ }^{10,11}$ Among them, the hook-nose-shaped papilla may hamper papillotome access the most, due to the orientation of the AV orifice. Therefore, earlier precut in DBC may reduce procedure time without increasing the frequency of complications, even in inexperienced hands. ${ }^{10}$

Second, regarding experience, European guidelines recommend that precut should be performed only by endoscopists who achieve selective biliary cannulation in $>80 \%$ of cases. ${ }^{4}$ However, the quality of evidence was low. Some reports revealed that the success rate of selective biliary cannulation by precut has been reported not to be associated with the experience level of the endoscopist. ${ }^{10,32,33}$ In our trial, all endoscopic procedures, including NK and Iso-Tome ${ }^{\circledR}$ precut, were performed by two experts because some experience with new instruments, such as Iso-Tome ${ }^{\circledR}$ may thus be needed.

Regarding limitations, this study was performed by experienced endoscopists at a single center. NK users may not be accustomed to using the Iso-Tome ${ }^{\circledR}$ and there is often a learning curve. In this study we did not estimate about the learning curve of IT-P. Based on our previous reports and experiences, we suggests at least 20 to 30 cases of IT-P might be needed to reach a sufficient level after training of NK-F. Second, not only were two different NK approaches used, but the precut starting position was different for the two methods. For a more precise comparison with IT-P, the conventional precut starting from the papillary orifice should be evaluated. However, because NK-F is safer than a precut starting from the orifice of the AV, IT-P was compared to NK-F. Further research to more fully evaluate the various devices and approaches is warranted. Third, among the DBC criteria, classification of the AV according to its bulging shape may be subject to bias, although there were no significant differences in distribution. In addition, a hooked papilla was included as a difficult factor that can complicate cannulation, contributing to initial higher cannulation failure rates even for experts. Finally, there should be more stringent indications for the use of IT-P and a training period should be investigated.

In conclusion, our results failed to prove the noninferiority of IT-P compared with NK-F regarding the primary successful selective biliary cannulation rate using the DBC criteria. IT-P also requires a longer successful cannulation time and procedure time. NK-F was more efficient than IT-P in cases of DBC. However, as a primary precut technique, IT-P in cases of DBC was safe and not associated with a higher complication rate even though the incision was started at the orifice of the AV. Users familiar with NK-precut starting from the orifice of the AV may use IT-P alternatively without the increasing risk of PEP.

\section{CONFLICTS OF INTEREST}

No potential conflict of interest relevant to this article was reported.

\section{ACKNOWLEDGEMENTS}

This work was supported by the Soonchunhyang University Research Fund.

\section{REFERENCES}

1. Tse F, Yuan Y, Moayyedi P, Leontiadis GI. Guidewire-assisted cannulation of the common bile duct for the prevention of postendoscopic retrograde cholangiopancreatography (ERCP) pancreatitis. Cochrane Database Syst Rev 2012;12:CD009662.

2. Williams EJ, Taylor S, Fairclough P, et al. Are we meeting the standards set for endoscopy? Results of a large-scale prospective survey of endoscopic retrograde cholangio-pancreatograph practice. Gut 2007;56:821-829.

3. Testoni PA, Testoni S, Giussani A. Difficult biliary cannulation during ERCP: how to facilitate biliary access and minimize the risk of post-ERCP pancreatitis. Dig Liver Dis 2011;43:596-603.

4. Testoni PA, Mariani A, Aabakken L, et al. Papillary cannulation and sphincterotomy techniques at ERCP: European Society of Gastrointestinal Endoscopy (ESGE) clinical guideline. Endoscopy 2016;48:657-683.

5. Lee YJ, Park YK, Lee MJ, Lee KT, Lee KH, Lee JK. Different strategies for transpancreatic septotomy and needle knife infundibulotomy due to the presence of unintended pancreatic cannulation in difficult biliary cannulation. Gut Liver 2015;9:534-539.

6. Yoo YW, Cha SW, Lee WC, Kim SH, Kim A, Cho YD. Double guidewire technique vs transpancreatic precut sphincterotomy in difficult biliary cannulation. World J Gastroenterol 2013;19:108114.

7. Yang MJ, Hwang JC, Yoo BM, et al. Wire-guided cannulation over a pancreatic stent versus double guidewire technique in patients 
with difficult biliary cannulation. BMC Gastroenterol 2015;15:150.

8. Siegel JH. Precut papillotomy: a method to improve success of ERCP and papillotomy. Endoscopy 1980;12:130-133.

9. Lopes L, Dinis-Ribeiro M, Rolanda C. Early precut fistulotomy for biliary access: time to change the paradigm of "the later, the better"? Gastrointest Endosc 2014;80:634-641.

10. Lee TH, Bang BW, Park SH, Jeong S, Lee DH, Kim SJ. Precut fistulotomy for difficult biliary cannulation: is it a risky preference in relation to the experience of an endoscopist? Dig Dis Sci 2011;56:1896-1903.

11. Lee TH, Hwang SO, Choi HJ, et al. Sequential algorithm analysis to facilitate selective biliary access for difficult biliary cannulation in ERCP: a prospective clinical study. BMC Gastroenterol 2014;14:30.

12. Freeman ML, DiSario JA, Nelson DB, et al. Risk factors for postERCP pancreatitis: a prospective, multicenter study. Gastrointest Endosc 2001;54:425-434.

13. Jin YJ, Jeong S, Lee DH. Utility of needle-knife fistulotomy as an initial method of biliary cannulation to prevent post-ERCP pancreatitis in a highly selected at-risk group: a single-arm prospective feasibility study. Gastrointest Endosc 2016;84:808-813.

14. Park SH, Kim HJ, Park DH, et al. Pre-cut papillotomy with a new papillotome. Gastrointest Endosc 2005;62:588-591.

15. Park SH, Park DH, Lee TH, et al. Feasibility of the mucosa-tracking technique in precut papillotomy with the Iso-Tome as an alternative to the needle-knife technique. Gut Liver 2010;4:76-83.

16. Cho YS, Park SH, Jun BG, et al. New technique of endoscopic sphincterotomy with Iso-Tome ${ }^{\circledast}$ to incise the distal papillary roof in patients with choledocholiths and choledochoduodenal fistula. Gut Liver 2015;9:231-238.

17. Jun BG, Lee TH, Jeong S, et al. One-step transfistula large versus conventional balloon dilation following precut fistulotomy in difficult biliary cannulation for the removal of biliary stones: a multicenter retrospective study. J Gastroenterol Hepatol 2014;29:15511556.

18. Kaffes AJ, Sriram PV, Rao GV, Santosh D, Reddy DN. Early institution of pre-cutting for difficult biliary cannulation: a prospective study comparing conventional vs. a modified technique. Gastrointest Endosc 2005;62:669-674.

19. Maeda S, Hayashi H, Hosokawa O, et al. Prospective randomized pilot trial of selective biliary cannulation using pancreatic guidewire placement. Endoscopy 2003;35:721-724.

20. Bailey AA, Bourke MJ, Kaffes AJ, Byth K, Lee EY, Williams SJ. Needle-knife sphincterotomy: factors predicting its use and the relationship with post-ERCP pancreatitis (with video). Gastrointest Endosc 2010;71:266-271.

21. Cotton PB, Eisen GM, Aabakken L, et al. A lexicon for endoscopic adverse events: report of an ASGE workshop. Gastrointest Endosc 2010;71:446-454.

22. Walker E, Nowacki AS. Understanding equivalence and noninferiority testing. J Gen Intern Med 2011;26:192-196.

23. Kawakami H, Kubota Y, Kawahata S, et al. Transpapillary selective bile duct cannulation technique: review of Japanese randomized controlled trials since 2010 and an overview of clinical results in precut sphincterotomy since 2004. Dig Endosc 2016;28 Suppl 1:77-95.

24. Lopes L, Dinis-Ribeiro M, Rolanda C. Safety and efficacy of precut needle-knife fistulotomy. Scand J Gastroenterol 2014;49:759-765.

25. Lee TH, Park DH. Endoscopic prevention of post-endoscopic retrograde cholangiopancreatography pancreatitis. World J Gastroenterol 2014;20:16582-16595.

26. Sundaralingam P, Masson P, Bourke MJ. Early precut sphincterotomy does not increase risk during endoscopic retrograde cholangiopancreatography in patients with difficult biliary access: a meta-analysis of randomized controlled trials. Clin Gastroenterol Hepatol 2015;13:1722-1729.e2.

27. Navaneethan U, Konjeti R, Venkatesh PG, Sanaka MR, Parsi MA. Early precut sphincterotomy and the risk of endoscopic retrograde cholangiopancreatography related complications: an updated meta-analysis. World J Gastrointest Endosc 2014;6:200-208.

28. Choudhary A, Winn J, Siddique S, et al. Effect of precut sphincterotomy on post-endoscopic retrograde cholangiopancreatography pancreatitis: a systematic review and meta-analysis. World J Gastroenterol 2014;20:4093-4101.

29. Cennamo V, Fuccio L, Zagari RM, et al. Can early precut implementation reduce endoscopic retrograde cholangiopancreatography-related complication risk? Meta-analysis of randomized controlled trials. Endoscopy 2010;42:381-388.

30. Gong B, Hao L, Bie L, Sun B, Wang M. Does precut technique improve selective bile duct cannulation or increase post-ERCP pancreatitis rate? A meta-analysis of randomized controlled trials. Surg Endosc 2010;24:2670-2680.

31. Baysal B, Akin H, Masri O, İnce AT, Senturk H. A novel round insulated tip papillotome as an alternative to the classic needle-knife for precut sphincterotomy in endoscopic retrograde cholangiopancreatography. Gastroenterol Res Pract 2015;2015:972041.

32. Robison LS, Varadarajulu S, Wilcox CM. Safety and success of precut biliary sphincterotomy: is it linked to experience or expertise? World J Gastroenterol 2007;13:2183-2186.

33. Akaraviputh T, Lohsiriwat V, Swangsri J, Methasate A, Leelakusolvong S, Lertakayamanee N. The learning curve for safety and success of precut sphincterotomy for therapeutic ERCP: a single endoscopist's experience. Endoscopy 2008;40:513-516. 